\title{
Efecto de la tipografía y presentación de párrafos de textos impresos sobre el aprendizaje a distancia en personas adultas
}

\author{
Julián Monge-Nájera', Víctor Hugo Méndez-Estrada² y Alfonso Villalobos Rodríguez ${ }^{3}$ \\ 1 Vicerrectoría de Investigación, Universidad Estatal a Distancia, UNED, San José, Costa Rica; julianmonge@gmail.com \\ 2 Programa de Investigación en Fundamentos de Educación a Distancia, UNED, Costa Rica; vmendez@uned.ac.cr \\ 3 Programa de Cognición y Lenguaje, Universidad de Costa Rica; avillalobosp@ice.go.cr
}

Recibido 3-VI-2009 Corregido 1-IV-2009 Aceptado 7-V-2009

\begin{abstract}
Effect of the typography and paragraph presentation of printed textbooks, on distance learning in adults. The effect of graphic presentation of texts on legibility has been studied, but its effect on learning is virtually unknown. We applied a control text and two treatments (variations in paragraphs and typography) to 169 students (67\% women) selected through a random process from a population of 2692 students from a freshmen's course at the State Distance University in San José, Costa Rica, in 2008. The information in the texts was new to the students. After 15 days allowed to study the texts, the students presented a written exam and completed an illustrated survey about paragraph and font characteristics that they preferred when studying. Neither the font nor the presentation of the paragraphs, or the sex of the students, had an effect on exam grade. The survey indicated that there is a subjective preference for 12-point Arial font, normal spacing between letters, single spacing between lines, page numbers located on page side, white background for text, titles in bold, and inclusion of subtitles, summary, highlighted key ideas, important words highlighted in bold, space to hand-write notes, and images printed in color. The font and paragraph presentation had no effect on learning, but affecte comfort when studying. We recommend that the study be repeated with students from other ages, courses, universities and backgrounds to see if our results can be generalized.
\end{abstract}

\section{KEY WORDS}

Distance learning, printed texts, graphic design purposes.

El esfuerzo que se dio luego de la Segunda Guerra Mundial por alfabetizar a la población mundial, estuvo acompañado de estudios sobre cómo se aprende a leer y cómo se puede aprovechar la fisiología de la lectura para optimizar el aprendizaje a partir de libros de texto. Tras llegarse a una serie de conclusiones sobre la relación entre características tipográficas (i.e. tipos de letra y su distribución en el papel) y legibilidad, como que lectores inexpertos se benefician de letras grandes y que el efecto de espaciamiento de letras y ancho de párrafos es mínimo (Richaudeau 1981), el interés en el tema disminuyó.

Sin embargo, el estudio de la fisiología de la lectura revivió a fines del siglo XX con la generalización del uso de computadoras, lo que llevó a estudiar los efectos de las características tipográficas sobre la lectura usando pantallas electrónicas en lugar de tinta sobre papel (Wang et al. 2007).
Experimentos con lectores de diversas edades usando tamaños de letra de 2 a 16 puntos presentados en pantallas, halló poca mejora en la legibilidad si se aumentaba el tamaño de letra más allá de los 6 puntos, aunque si se le preguntaba a las personas cuáles letras les resultaban más cómodas para leer, respondieron principalmente que eran las de 8 a 12 puntos (Darroch et al. 2005). En experimentos con lectura en pantalla, pruebas con tamaños de letra desde 10 hasta 13 puntos hallaron que en tamaños superiores a 7,8 puntos no hay mejora en la rapidez de lectura (Wang et al. 2007).

En el caso de personas con capacidad visual disminuida también existe alguna información sobre el efecto de la tipografía en la lectura. Por ejemplo, un experimento con letras de varios tamaños (10-16 puntos) y tipos (Foundry Form Sans; Helvética, Tiresias y Times New Roman), así 
como con anchos de párrafo (35; 70 y 90 letras) halló que ni la tipografía ni el ancho de párrafo tenían efecto sobre la lectura. Hubo un efecto favorable sobre la rapidez de lectura al aumentar el tamaño de letra de 10 a 16 puntos, pero fue mínimo: $11 \%$. Si se usaran letras de 16 puntos para las personas de más de 65 años de edad con visión disminuida, se aumentaría del 88 al 94\% la proporción de esa población capaz de leer fluidamente (Rubin et al. 2006).

En cuanto al efecto de la edad sobre la legibilidad de textos impresos, se ha descubierto que las personas adultas son más sensibles que los niños a las formas de las letras y fijan ambos ojos en la misma letra con menos frecuencia que los niños (Blythea et. al. 2006, Burgund 2008). Los adultos de mayor edad tienen además una mejor capacidad de ignorar información distractora dentro del texto, trátese de palabras sueltas o frases completas (Kemper y McDowd 2006, Kemper et al. 2008).

Aun cuando los libros de texto, impresos o en pantalla, se lean fluidamente, ¿existe efecto de la tipografía sobre el aprendizaje en sí? Aunque coinciden en que fuera del tamaño de letra, ninguna de las características tipográficas estudiadas afecta la legibilidad de los textos, ninguno de los estudios publicados hasta ahora a nivel mundial responde a esta pregunta. Se desconoce el efecto de las características tipográficas sobre el paso que sigue a la lectura, y que más interesa a la enseñanza: el aprendizaje.

En la Universidad Estatal a Distancia (UNED) de Costa Rica se ha consultado cualitativamente al estudiantado sobre los recursos gráficos en los textos (Cruz et al. 2008), pero no se ha estudiando su relación con el rendimiento académico; por lo tanto, este informe es, hasta donde sabemos, el primero que responde a la pregunta sobre un posible efecto de la tipografía de los textos impresos en el aprendizaje por parte de adultos. Aunque nuestro estudio está limitado a la población , creemos que será de interés general debido a la carencia de literatura sobre este tema a nivel mundial.

\section{METODOLOGÍA}

\section{Población muestreada}

Se eligió una muestra aleatoria de 615 estudiantes dentro de una población de 2692 estudiantes, correspondiente a todos los centros universitarios y sub-sedes de la UNED que contaban con estudiantes matriculados en el curso Técnicas de Estudio a Distancia y de Investigación (código 022, segundo cuatrimestre del 2008). Los criterios para elegir esta población fueron:

1. Que se tratara de un grupo con suficientes estudiantes para obtener una muestra válida aun con las bajas tasas de participación y retorno que sabemos por experiencia que se tienen en la UNED para este tipo de estudios.

2. Que el curso tuviera estudiantes en la mayor parte de Costa Rica, para que los resultados fueran más generalizables geográficamente.

3. Que el estudio aportara información en un área particularmente débil de esta universidad, que es la retención de estudiantes nuevos (a los cuales va dirigido este curso en particular).

Los centros universitarios muestreados fueron Alajuela, Atenas, Cañas, Cartago, Centro Universitario La Reforma, Ciudad Neily, Desamparados, Guápiles, Heredia, Jicaral, La Cruz, Liberia, Limón, Monteverde, Nicoya, Orotina, Osa, Palmares, Pavón, Puntarenas, Puriscal, Quepos, San Carlos, San Isidro, San José, San Marcos, San Vito, Santa Cruz, Sarapiquí, Shiroles, Siquirres, Tilarán, Turrialba y Upala.

En total, 169 estudiantes devolvieron los instrumentos e hicieron el examen. La validez de la muestra se estableció a partir de la fórmula: $\mathrm{N}=(1,96 * \mathrm{DE}) 2 / \mathrm{E}$

Dónde $\mathrm{N}$ corresponde al tamaño de la muestra, DE desviación estándar y E error de muestreo (5\%). Como la desviación estándar fue de 15,95 la población recomendada es de195 estudiantes, cercana a la obtenida en el estudio ( $n=169)$.

\section{Instrumentos}

Los estudiantes fueron aleatoriamente asignados a tres grupos:

1. Control: folleto A, tipografía sencilla (Apéndice 1).

2. Tratamiento 1: variantes en las letras (Apéndice 2).

3. Tratamiento 2: variantes en los párrafos (Apéndice 3).

Tras recibir los textos didácticos impresos, tuvieron 15 días para estudiar los materiales, luego de lo cual se les aplicó un examen de conocimientos. Para medir únicamente el efecto de la tipografía, era necesario eliminar el efecto de conocimientos previos sobre el tema, por lo que los textos eran sobre un tema por completo desconocido para ellos: la ecología de Epiperipatus n. sp., una especie de gusano recientemente descubierta y aun no descrita por la ciencia, la cual solo ha sido estudiada por el autor principal (J. Monge-Nájera, datos sin publicar).

El examen (Apéndice 4) constaba de 18 preguntas con varias opciones de respuesta cada una, de la cual sólo una respuesta era correcta y se debía marcar con $\mathrm{X}$, por lo que la calificación no estaba sujeta a interpretación subjetiva de las respuestas. Se aplicó también una encuesta donde aparecían diversas opciones tipográficas, preguntando cuáles resultaban preferidas (Apéndice 5). 
Nota: la pregunta 1 del cuestionario, referente a letra serifada, se eliminó del estudio pues por un error de diagramación el material no contenía letra claramente serifada.

\section{RESULTADOS}

El $67 \%$ de las participantes son mujeres. El $44 \%$ de las personas solo leyó el material una vez, el $43 \%$ lo estudió de 2 a 4 horas y el $8 \%$ de 4 a 6 horas.

Las puntuaciones obtenidas en el examen (Normalidad: sesgo hacia valores positivos, Kolmogorov-Smirnov $\mathrm{D}=1,584 ; \mathrm{p}<0,013$ ) no fueron afectadas por el sexo (Levene $=0,001 ; p>0,979)$ ni por el tipo de folleto (Levene $=$ 0,$358 ; p>0,700$ ).

La nota media de las mujeres fue 53,94 (Desviación Estándar DE 16,17) y de los hombres 51,22 (DE 15,52). La nota media por folleto fue A 55,46 (DE 15,13); B 53,02 (DE $17,04)$ y $C 50,00$ (DE 15,67).

Las proporciones de respuestas correctas en cada pregunta fueron semejantes en los tres folletos (Cuadro 1)

Independientemente de que la tipografía no afecte la nota obtenida en la prueba, la encuesta indicó que sí existe una preferencia subjetiva por la letra Arial de 12 puntos, espaciado normal entre letras, espacio sencillo entre renglones, numeración lateral de las páginas, fondo blanco para el texto, títulos con negrilla en lugar de letra corriente, y textos con estas seis características: subtítulos, resumen, ideas clave resaltadas, palabras importantes resaltadas con negrita, espacio para hacer anotaciones e imágenes en color (Cuadro 2, se aplicó a cada caso una prueba de chi-cuadrado del 0,05 y en todos estos casos el resultado fue significativo).

No hay preferencia marcada por ubicar palabras indicadoras arriba o abajo del texto (Cuadro 2, se aplicó a cada caso una prueba de chi-cuadrado del 0,05 y en todos este caso el resultado no fue significativo).

\section{DISCUSIÓN}

Al no existir estudios previos sobre el efecto de la tipografía sobre la nota obtenida en exámenes por estudiantes a distancia, resulta imposible comparar nuestros resultados con los de otros autores. El estudio previo de Cruz et al. (2008), reportó preferencia por algunos recursos didácticos útiles para estudiar los contenidos en un sistema a distancia, pero no evaluó por medio de alguna prueba si influyen en el rendimiento académico. Por ello, analizamos nuestros resultados con base en estudios sobre legibilidad y preferencia, ya que puede suponerse que la legibilidad y preferencia por dichos recursos de un texto tiene efecto sobre la capacidad del lector para aprender el contenido.

El tamaño de la letra, siempre y cuando supere los 6 puntos para tinta sobre papel, y los 7,8 puntos para pantalla, es suficiente para una lectura fluida, excepto cuando se trata de personas con visión reducida, por ejemplo por razones de edad avanzada (Rubin et. al. 2006, Wang et. al. 2007). Nuestros resultados son coherentes con la idea de que esa generalización puede aplicarse también al aprendizaje a distancia: siempre que las letras sean razonablemente visibles (7 puntos o más), su tamaño no afecta el aprendizaje.

Los adornos de las letras, y su forma, así como el ancho de los párrafos, tampoco afectan la legibilidad (Rubin et. al. 2006). Igualmente, esas características tipográficas carecen de efecto sobre el aprendizaje. En la UNED, 41\% del estudiantado prefiere que se incluyan varios tipos de letras en los textos impresos (Cruz et al. 2008). Como la edad afecta algunas características de la lectura, siendo más probable que los niños se distraigan con adornos de las letras y símbolos adicionales en los textos (Blythea et. al. 2006, Burgund 2008, Kemper y McDowd 2006, Kemper et al. 2008), es posible que nuestros resultados no se extiendan a los niños, y para saberlo es necesario un estudio experimental que mida el aprendizaje de un tema en niños usando diferentes opciones tipográficas que enfaticen elementos distractores como letra negrita o cursiva y serifado de letras.

¿Pudo haber un efecto de desinterés de los estudiantes, que hiciera que no se esforzaran en estudiar porque se trataba de un experimento?

Considerando que se trata de estudiantes nuevos, que incluso en los exámenes que valen para la nota final tienen poco éxito (la tasa de deserción inicial en la UNED es del 70,8\%) (Umaña 2005), la nota promedio obtenida indica que no se dio ese efecto. Pero incluso si se hubiera encontrado ese efecto, habría afectado por igual al grupo control y a los tratamientos, ya que estos se distribuyeron al azar, por lo que nuestro resultado seguiría siendo válido.

Los textos más recientes de la UNED pueden hacer uso de muchos recursos gráficos (e.g. Monge-Nájera 2007, Cruz et al. 2008) y sus estudiantes indicaron que $56 \%$ prefieren la existencia de espacios en la página para hacer anotaciones, $68 \%$ desean que se usen recursos ilustrativos para destacar las ideas principales; $64 \%$ gustan del uso de color en el texto y $41 \%$ desean que se incluyan varios tipos de letras (Cruz et al. 2008). Sin embargo, desde el punto de vista del aprendizaje medido en un examen típico de la UNED, que es de naturaleza reproductiva, no hay efecto 


\section{CUADRO 1}

Respuestas correctas (\%) de cada ítem del examen según el tratamiento

\begin{tabular}{|c|c|c|c|}
\hline Pregunta & Folleto $\mathrm{A}$ & Folleto B & Folleto C \\
\hline $\begin{array}{l}\text { El fósil descubierto en Chicago fue el primero que presento la } \\
\text { siguiente característica }\end{array}$ & 41,3 & 32,0 & 26,7 \\
\hline Los onicóforos predominan en el siguiente tipo de ecosistema & 36,1 & 32,7 & 31,3 \\
\hline $\begin{array}{l}\text { La característica principal que emplean los onicóforos para atrapar } \\
\text { a sus presas es la siguiente }\end{array}$ & 35,6 & 31,5 & 32,9 \\
\hline $\begin{array}{l}\text { A continuación se le presentan los siguientes dibujos de animales } \\
\text { invertebrados. El número del dibujo que representa a un } \\
\text { onicóforo es el siguiente }\end{array}$ & 37,1 & 32,1 & 30,7 \\
\hline $\begin{array}{l}\text { Una característica que los onicóforos comparten con los anélidos } \\
\text { es la presencia de }\end{array}$ & 32,8 & 35,9 & 31,3 \\
\hline Las hembras de onicóforos presentan diapausa, lo que les permite & 39,3 & 28,6 & 32,1 \\
\hline Los onicóforos y los artrópodos se diferencian en lo siguiente & 39,7 & 24,1 & 36,2 \\
\hline $\begin{array}{l}\text { La distribución actual de los onicóforos coincide con la vegetación } \\
\text { de la siguiente era geológica }\end{array}$ & 37,6 & 33,3 & 29,0 \\
\hline $\begin{array}{l}\text { Estructura de los onicóforos que ha servido de base para explicar } \\
\text { su biodiversidad y modo de reproducción". La afirmación anterior } \\
\text { se refiere a }\end{array}$ & 29,4 & 23,5 & 47,1 \\
\hline $\begin{array}{l}\text { El siguiente lugar se considera como el posible centro de radiación } \\
\text { evolutiva de los onicóforos }\end{array}$ & 34,4 & 32,8 & 32,8 \\
\hline Los onicóforos antiguos vivían en el siguiente hábitat & 39,6 & 26,7 & 33,7 \\
\hline Los onicóforos actuales se parecen a los poliquetos en lo siguiente & 44,1 & 22,5 & 33,3 \\
\hline $\begin{array}{l}\text { Una de las familias que agrupan a los onicóforos costarricenses y } \\
\text { del mundo es la siguiente }\end{array}$ & 34,4 & 32,8 & 32,8 \\
\hline $\begin{array}{l}\text { Las protuberancias presentes en el cuerpo de los onicóforos sirven } \\
\text { para }\end{array}$ & 42,9 & 28,6 & 28,6 \\
\hline $\begin{array}{l}\text { Una característica exclusiva de la partenogénesis que presentan } \\
\text { los onicóforos es la siguiente }\end{array}$ & 37,9 & 28,8 & 33,3 \\
\hline $\begin{array}{l}\text { Una estructura que solo estaba presente en los onicóforos } \\
\text { primitivos era }\end{array}$ & 36,7 & 32,9 & 30,4 \\
\hline $\begin{array}{l}\text { Para lograr adaptarse a los ecosistemas actuales, los onicóforos } \\
\text { modernos perdieron las siguientes estructuras corporales }\end{array}$ & 33,0 & 37,4 & 29,7 \\
\hline Para evitar la desecación, los onicóforos & 43,1 & 29,4 & 27,5 \\
\hline
\end{tabular}




\section{CUADRO 2}

Comparación porcentual de las respuestas a cada ítem del cuestionario de opinión de tipografías, de acuerdo con la distribución de respuestas por folleto.

Ítemes del cuestionario
Revise cada uno de los textos incluidos en los recuadros
e indique cuál es el texto con el tipo de letra que más le
agrada

Escoja la opción con el tamaño de letra que más le agradaría para leer libros de texto de la UNED

En los siguientes cuadros usted podrá observar un texto dispuesto con diferentes espacios entre las letras, por favor escoja el que más le agrade

Escoja la opción del texto con el espacio entre renglones que sea de su agrado

Indique cuál es la opción que le parece más apropiada para numerar las páginas de los libros editados por la UNED

Señalización

De los siguientes dos textos escoja el que cree que más le favorece en su aprendizaje

Se le presentan dos ejemplos de texto con distintos tipos de títulos, por favor escoja la opción de su agrado

¿Cuál de los dos cuadros de abajo le ayudarían más al momento de aprender los contenidos para un examen?

¿Cuál de los dos cuadros de abajo le ayudarían más al momento de aprender los contenidos para un examen? Resumen

¿Cuál de los dos cuadros de abajo le ayudarían más al momento de aprender los contenidos para un examen? Idea clave
Opciones de cada ítem Porcentaje de personas que marcó cada ítem, total en cada caso 169 personas

Arial 72,8

Times New Roman $\quad 13,6$

Ninguna $\quad 12,4$

81,2

$10 \quad 28,4$

$12 \quad 69,8$

Ninguna 0

Normal $\quad 85,2$

$+40 \quad 3,6$

Ninguna $\quad 10,1$

Doble $\quad 18,9$

sencillo $\quad 71,6$

Ninguna $\quad 8,3$

Arriba centrada $\quad 15,4$

Lateral $\quad 71,6$

Ninguna $\quad 11,8$

Arriba 46,2

Abajo 45,6

Ninguna $\quad 6,5$

Con fondo 35,5

Sin fondo 56,2

Ninguna $\quad 6,5$

Sin negrilla $\quad 4,1$

Con negrilla 93,5

Ninguna 1,2

Con división 96,4

Sin división 1,2

Ninguna $\quad 1,2$

Ausente 16

Presente 77,5

Ninguno $\quad 5,9$

Presente 93,5

Ausente 3,6

Ninguna $\quad 2,4$ 


\section{CUADRO 2 (Continuación...)}

¿Cuál de los dos cuadros de abajo le ayudarían más al momento de aprender los contenidos para un examen? Conceptos clave resaltados en negrilla

De las siguientes opciones, por favor escoja la que le resulte más agradable. Recuadro para hacer anotaciones

De las siguientes figuras, por favor indique la que usted considera que le ayuda mejor en su aprendizaje

$\begin{array}{lc}\text { Ausente } & 4,1 \\ \text { Presente } & 94,7 \\ \text { Ninguna } & 0,6 \\ \text { Presente } & 56,8 \\ \text { Ausente } & 34,3 \\ \text { Ninguna } & 7,7 \\ \text { Sin color } & 0,6 \\ \text { Con color } & 98,2 \\ \text { Ninguna } & 0,6\end{array}$

incorporadas. Cualquier error que quede en el trabajo es responsabilidad de los autores.

examen, que es realmente el parámetro que define el éxito o fracaso académico desde el punto de vista práctico.

La tipografía y presentación de párrafos no tuvieron efecto sobre la nota obtenida en el examen en estos estudiantes adultos de educación a distancia, la preferencia subjetiva por cierta letra, apoyos tipográficos, espacio para anotaciones e imágenes en color, debe tomarse en cuenta si se desea que los textos sean más motivadores e inciten a su lectura. Aunque esas características no afecten la nota obtenida en los exámenes, sí harán más agradable el estudio y podrían contribuir a disminuir la tasa de deserción en estudiantes universitarios a distancia.

Nuestro estudio no tenía como objetivo analizar aspectos cualitativos del aprendizaje, sino responder dos preguntas muy concretas para la población estudiada:

1. ¿Afecta la presentación de los textos impresos?

2. ¿Presenta el estudiantado preferencia por algunas características tipográficas?

Creemos que la metodología aplicada permitió hacerlo de manera científicamente válida y como siguiente paso recomendamos que el estudio se repita con estudiantes de otras edades, cursos, universidades e historiales para saber si nuestros resultados son generalizables a otras poblaciones estudiantiles.

\section{AGRADECIMIENTOS}

Agradecemos a Nubia Navarro por las recomendaciones sobre el texto y el examen, así como el apoyo de Léster Osorno para aplicar los materiales entre el estudiantado de su cátedra. También agradecemos el trabajo de Maribel Zúñiga en la preparación de los textos y examen, y a Diego Quirós y Dagoberto Núñez por sugerencias para mejorar una versión anterior, parte de las cuales fueron

\section{RESUMEN}

Aunque se ha estudiado el efecto de la presentación gráfica de textos sobre la legibilidad, su efecto sobre el aprendizaje es prácticamente desconocido. Aplicamos un texto control y dos tratamientos (variaciones en los párrafos y variaciones en la tipografía) a 169 estudiantes (67\% mujeres) elegidos mediante un procedimiento aleatorio dentro de una población de 2692 estudiantes de un curso inicial en la Universidad Estatal a Distancia de San José, Costa Rica, en 2008. La información en los textos era nueva para los estudiantes. Tras 15 días de plazo para estudiar los textos, respondieron a un examen escrito sobre el tema de los textos y llenaron una encuesta ilustrada sobre cuáles presentaciones de párrafo y tipografía les resultaban más agradables al estudiar. Ni la tipografía, ni la presentación de los párrafos, ni el sexo de los estudiantes, tuvieron efecto sobre la nota obtenida en el examen. La encuesta indicó que sí existe una preferencia subjetiva por la letra Arial de 12 puntos, espaciado normal entre letras, espacio sencillo entre renglones, numeración lateral de las páginas, fondo blanco para el texto, títulos con negrilla en lugar de letra corriente, y textos con estas seis características: subtítulos, resumen, ideas clave resaltadas, palabras importantes resaltadas con negrita, espacio para hacer anotaciones a mano e imágenes en color. La tipografía y presentación de párrafos no tuvieron efecto sobre el aprendizaje, pero sí sobre la comodidad al estudiar. Recomendamos que el estudio se repita con estudiantes de otras edades, cursos, universidades e historiales para saber si nuestros resultados son generalizables.

\section{PALABRAS CLAVE}

Aprendizaje a distancia, textos impresos, efectos del diseño gráfico.

\section{REFERENCIAS}

Blythea, H.I., S.P. Liversedgea, H. Josepha, S.J. Whitea, J.M. Findlaya \& K. Raynerb. 2006. The binocular coordination of eye movements during reading in children and adults. Vision Research 46: 3898-3908.

Burgund, E.D. 2008. Letter-specific processing in children and adults matched for reading level. Acta Psychologica 129: 66-71. 
Cruz, A. G. D’Agustino \& J. Meza. 2008. Elementos y características del material impreso que favorece la formación y el aprendizaje a distancia en la UNED de Costa Rica. Resultados específicos por escuela y nivel de carrera. Innovación Educativa 10: 41-57.

Darroch, I., J. Goodman, S. Brewster \& P. Gray. 2005. The effect of age and font size on reading text on handheld computers. Lecture Notes Computer Science 3585: 253-266.

Kemper, S. \& J. McDowd. 2006. Eye movements of young and older adults while reading with distraction. Psychological Aging 21: 32-39.

Kemper, S., J. McDowd, K. Metcalf \& C.J. Liu. 2008. Young and older adults' reading of distracters. Education and Gerontology 34: 489-502.

Monge-Nájera, J. 2007. El ser humano en su entorno. Universidad Estatal a Distancia, San José, Costa Rica.

Richaudeau, F. 1981. Concepción y producción de manuales escolares. Guía práctica. Bogotá, Colombia, Secretaría Educativa del Convenio "Andrés Bello", Centro Regional para el Fomento del Libro en América Latina y el Caribe y Editorial de la UNESCO.

Rubin, G.S., M. Feely, S. Perera, K. Ekstrom \& E. Williamson. 2006. The effect of font and line width on reading speed in people with mild to moderate vision loss. Ophtalmology Physics. and Optics 26: 545-554.

Umaña C, R. 2005. Deserción de los estudiantes nuevos del PAC 2000-I en la Universidad Estatal a Distancia de Costa Rica. Centro de Mejoramiento de los Procesos Académicos, Universidad Estatal a Distancia, San José, Costa Rica (informe interno sin publicar).

Wang, C.X., F. Lü, D. Xu, J. Chen, R.Z. Xie, L. Zhu \& J. Qu. 2007. A comparison of Chinese reading parameters among rapid serial visual presentation, full screen and printed displays. Zhonghua Yan Ke Za Zhi 43: 704-708.

Este artículo fue editado por Zaidett Barrientos 


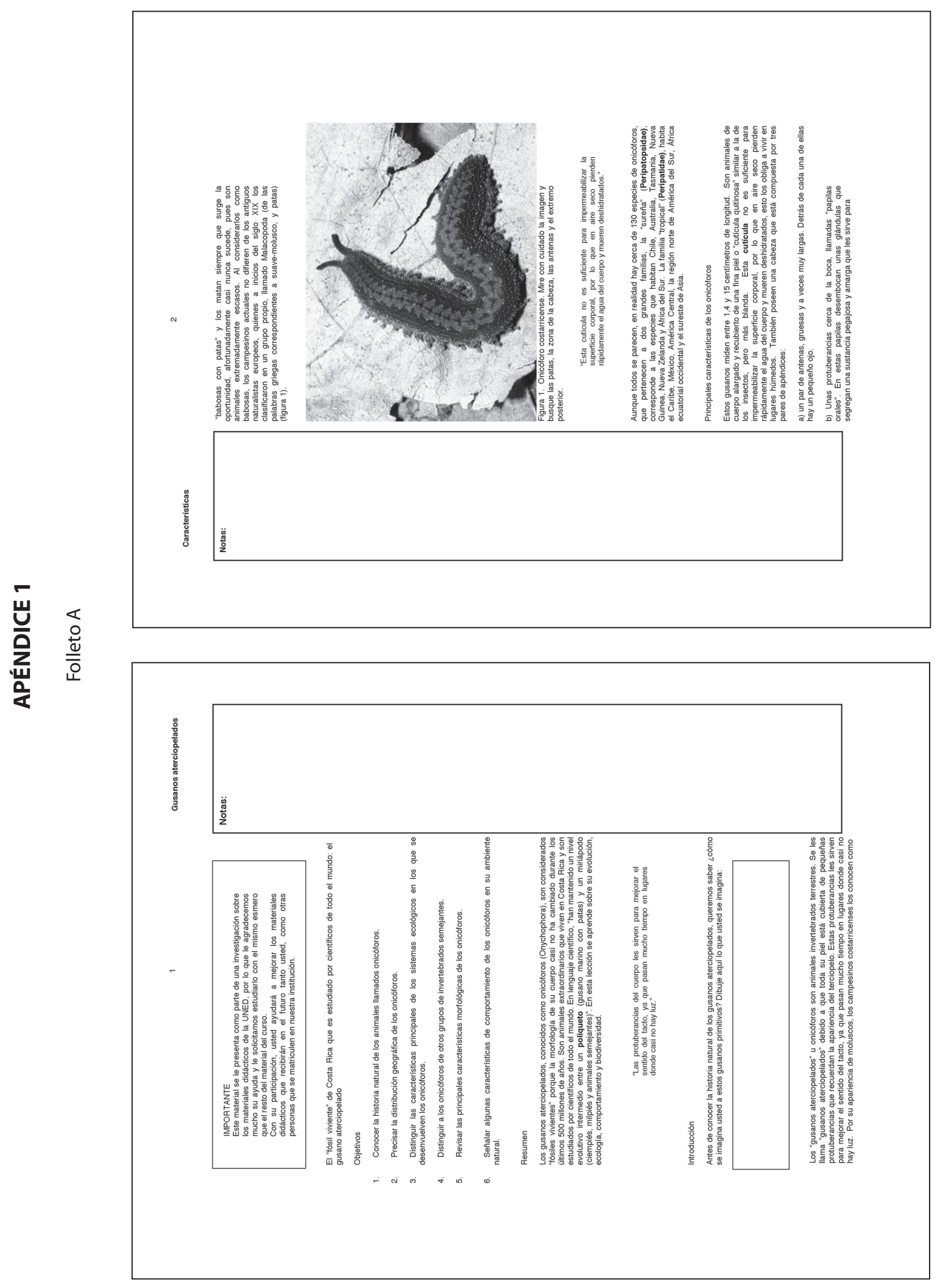



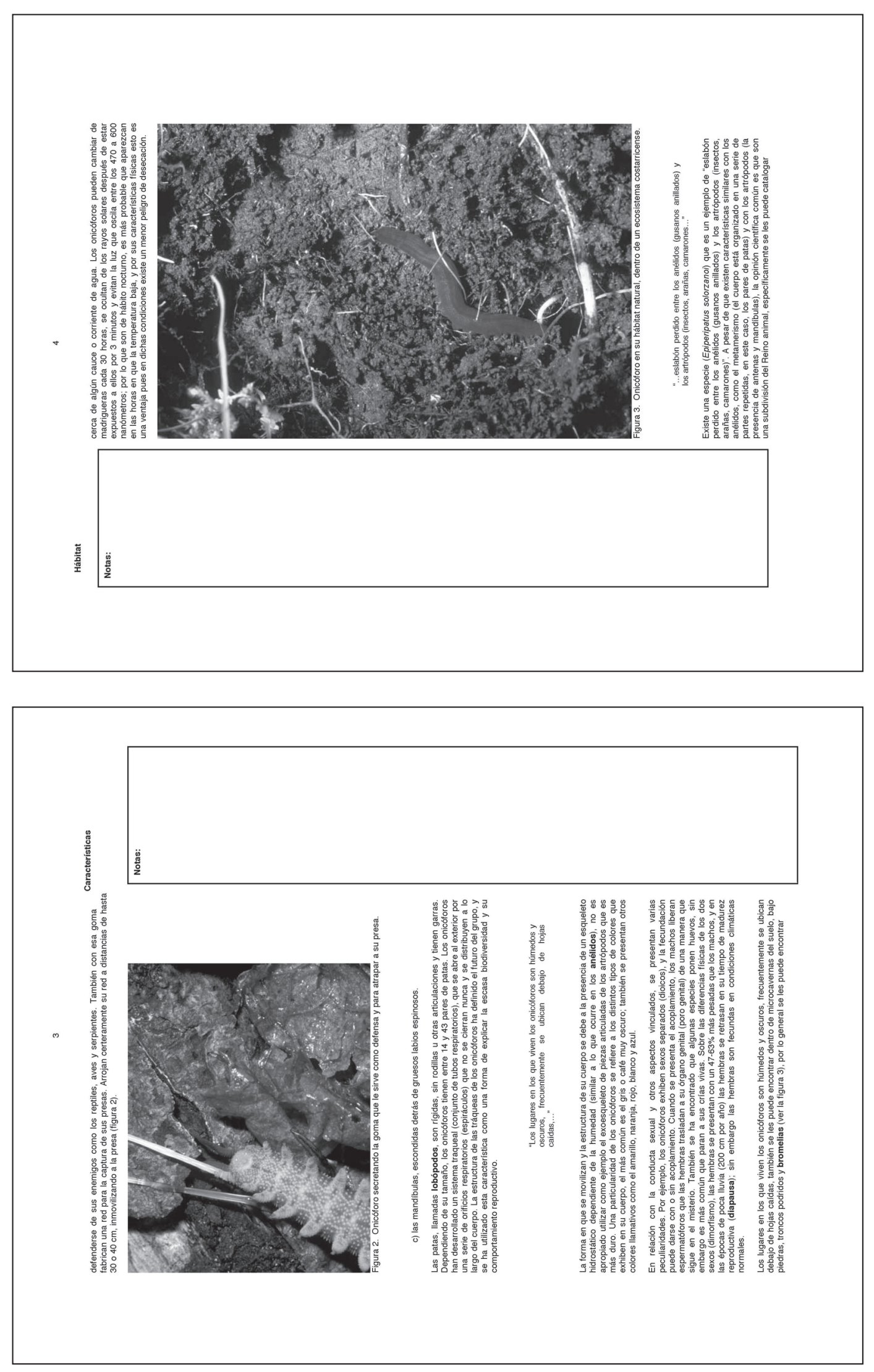

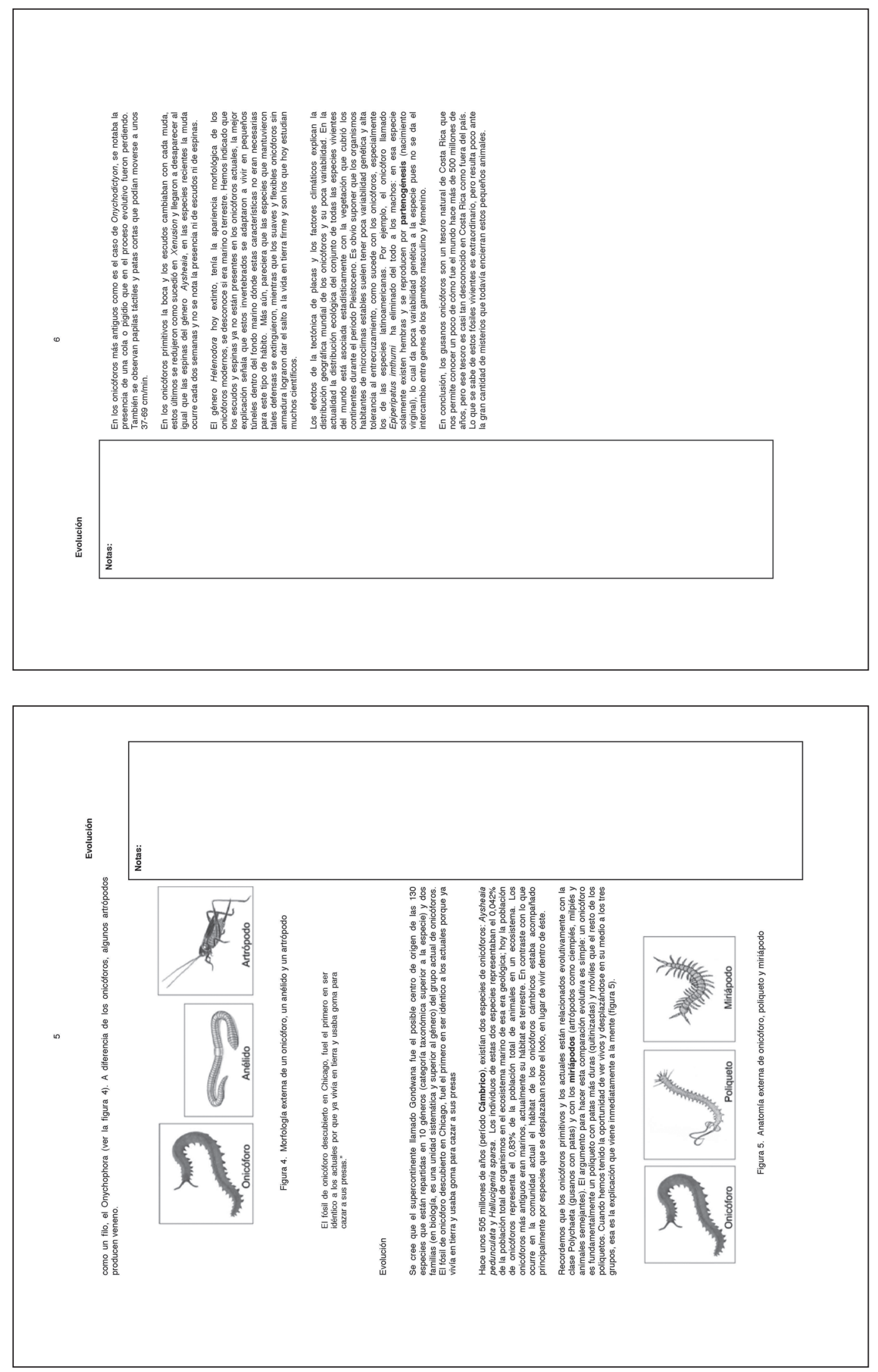

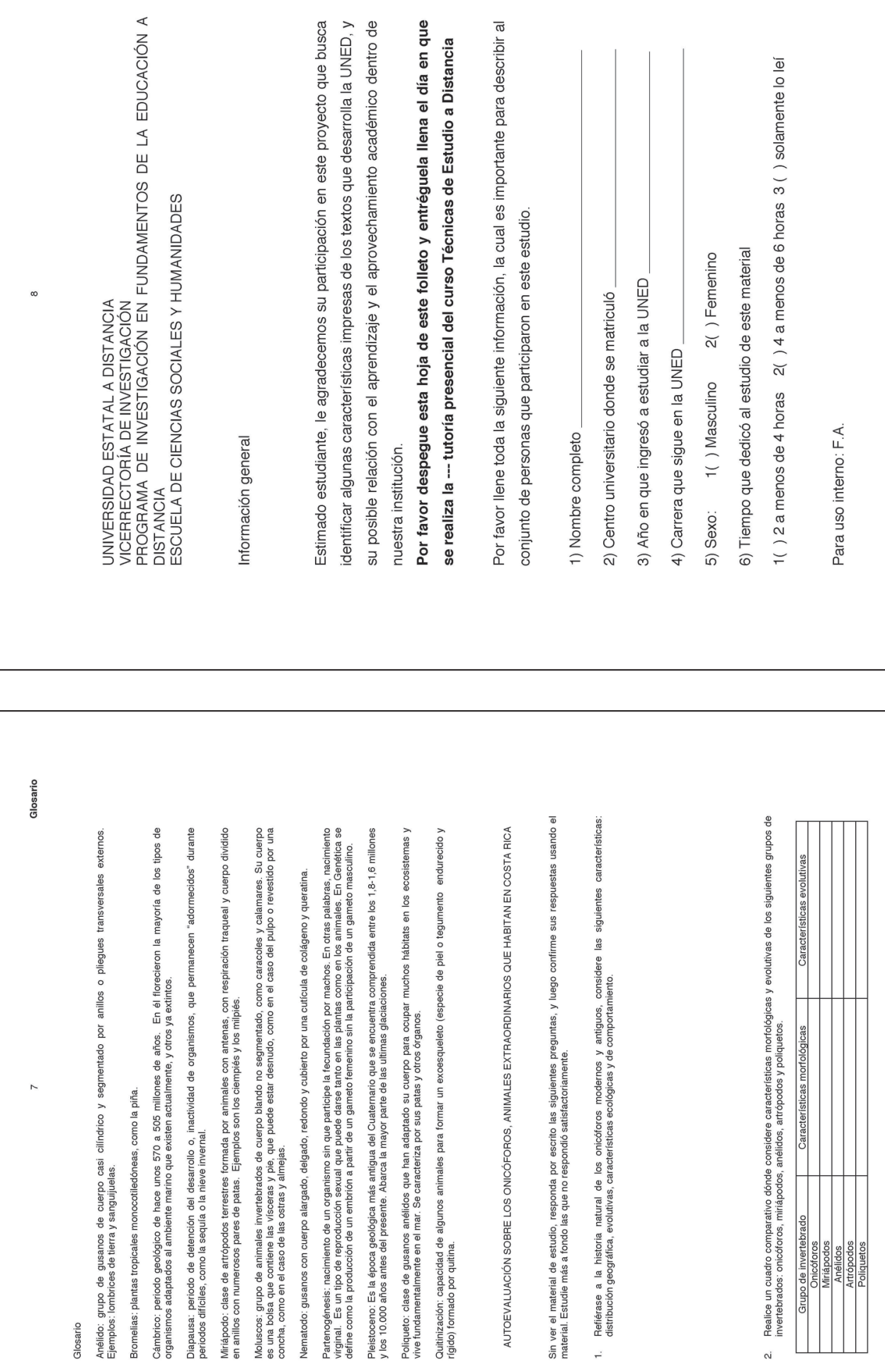


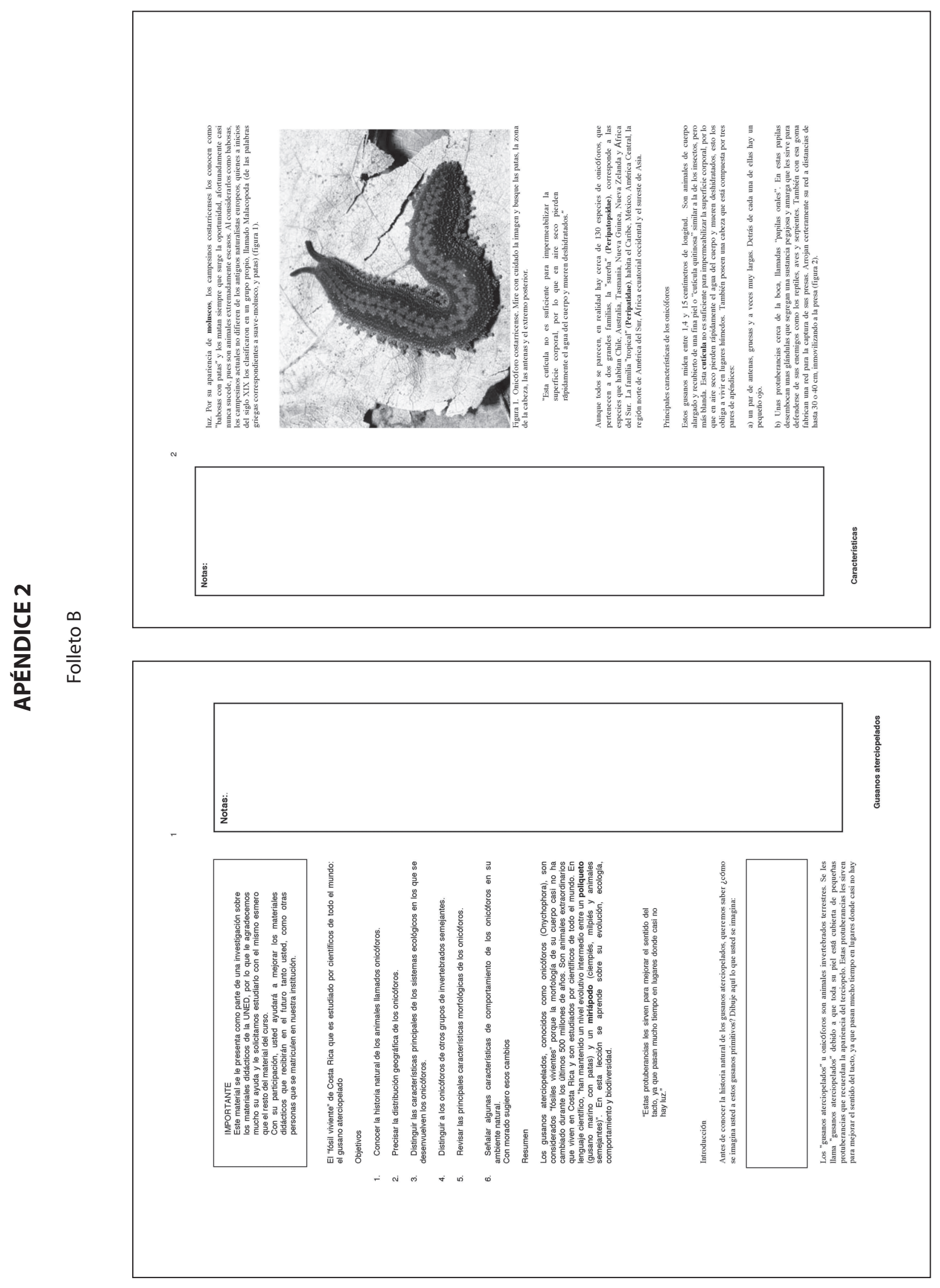




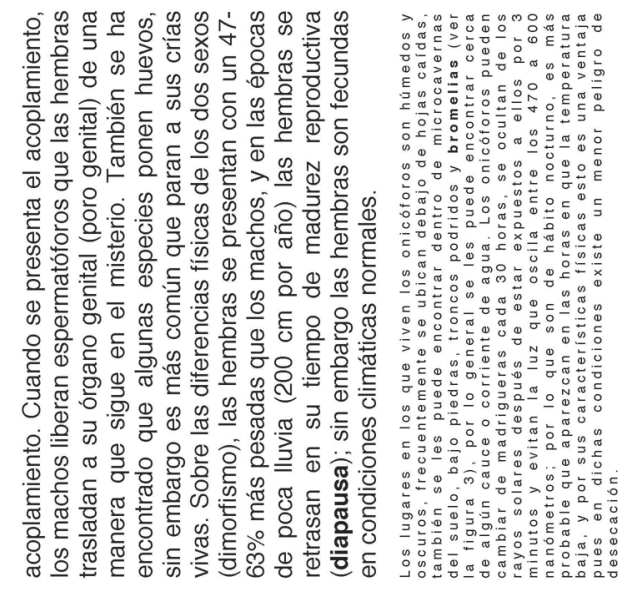

을
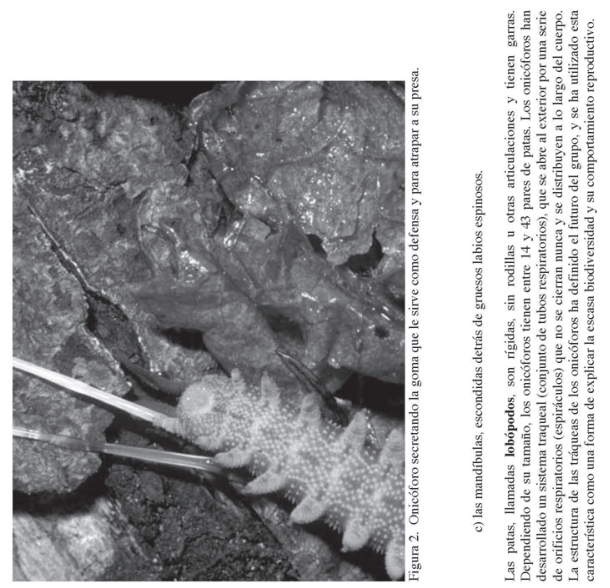

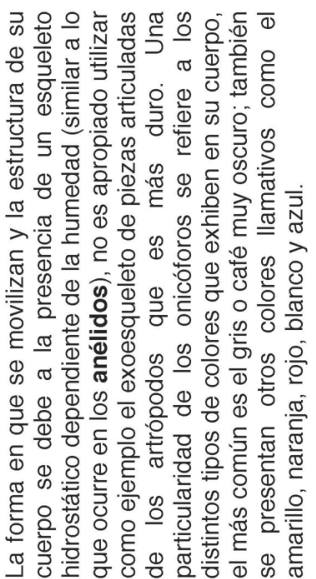

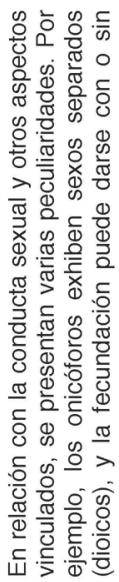



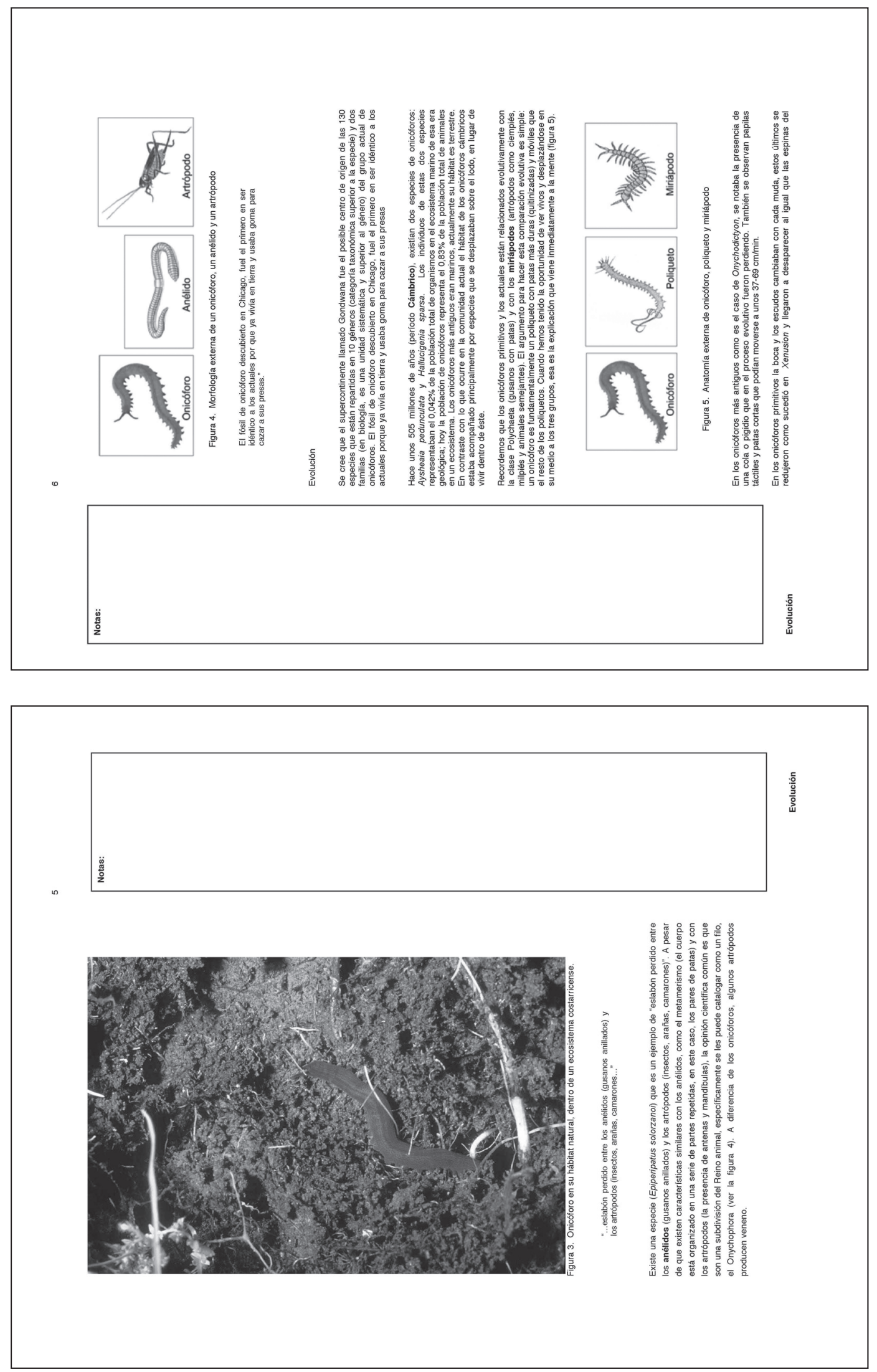

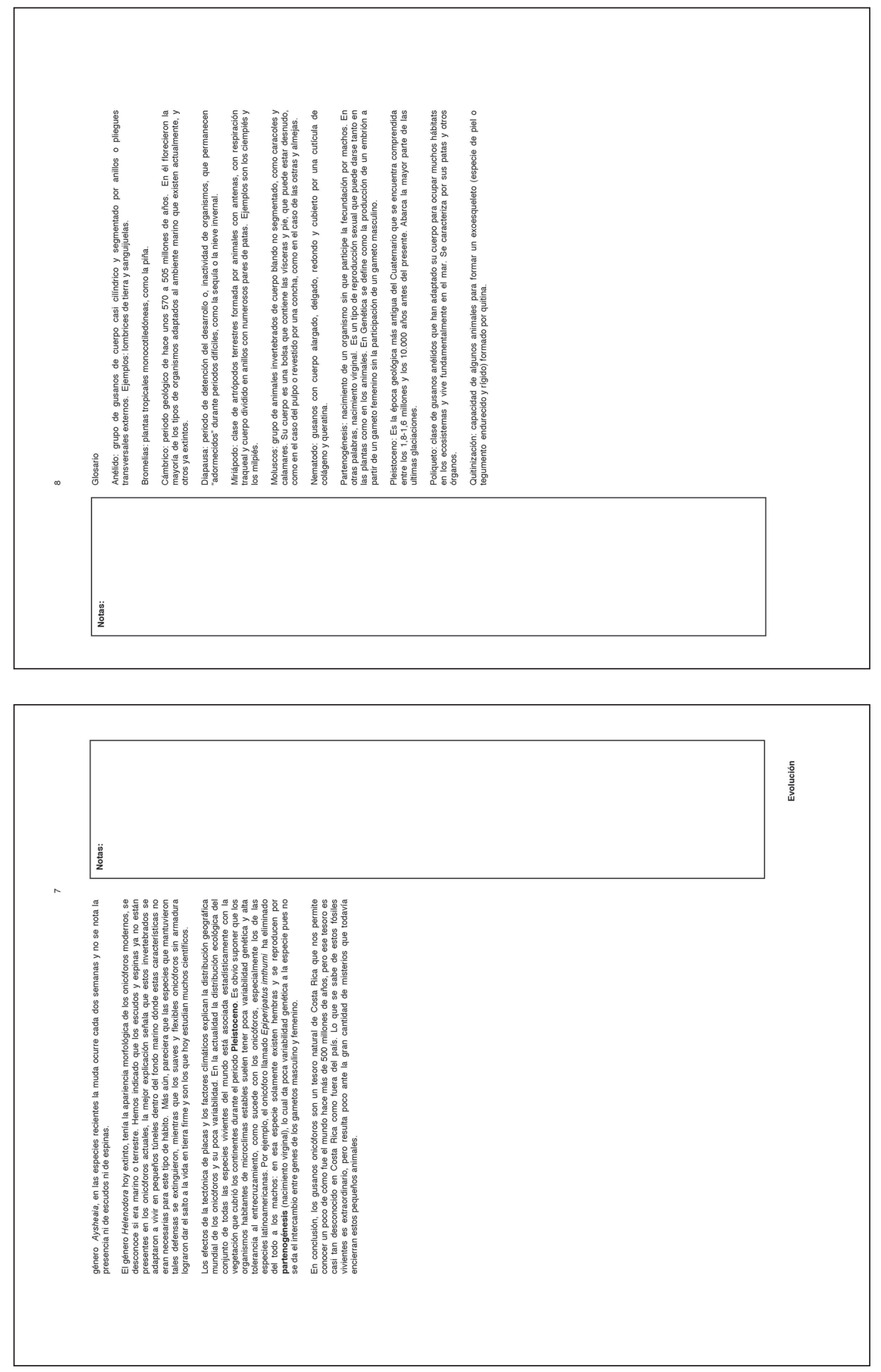

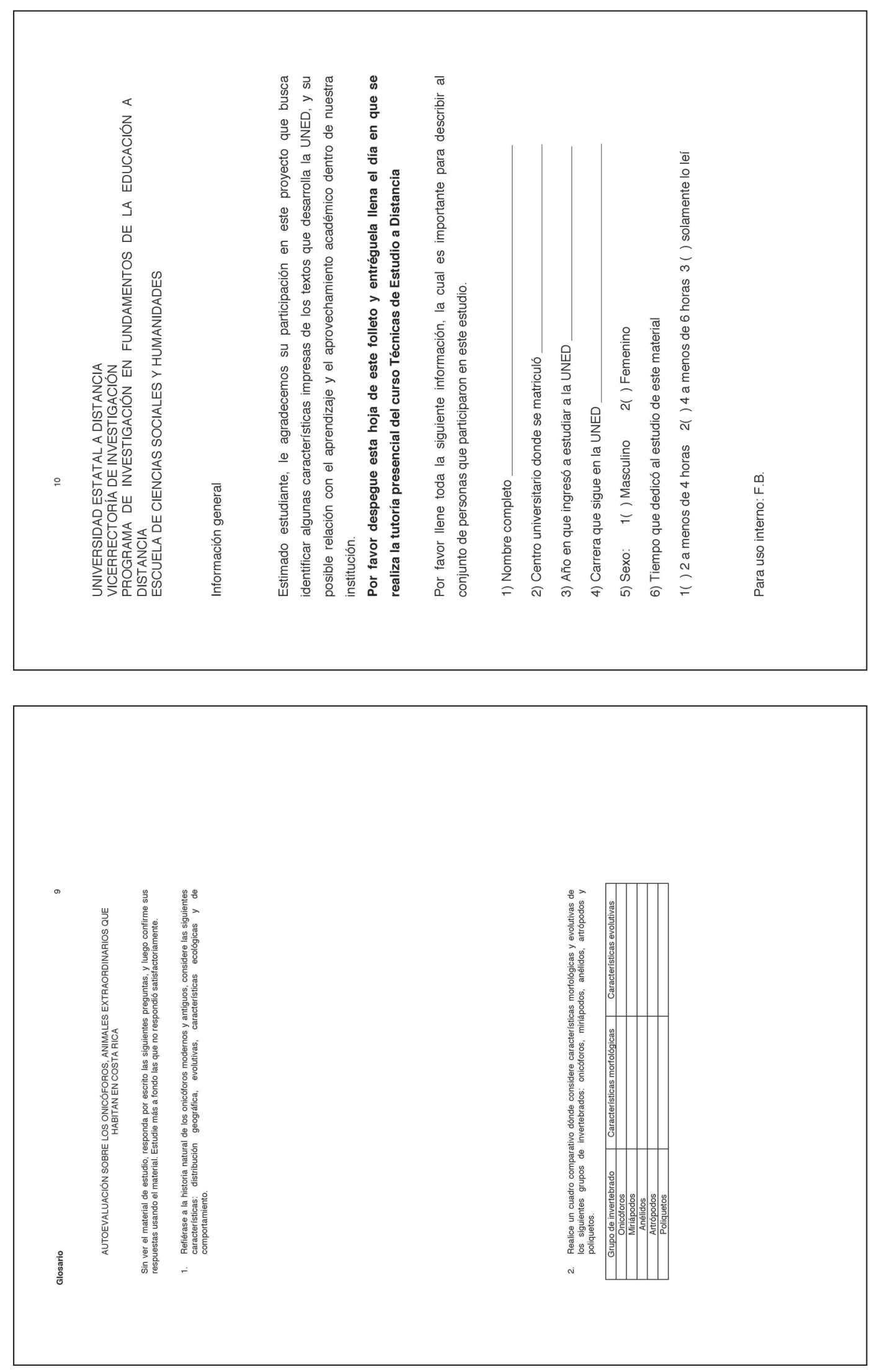


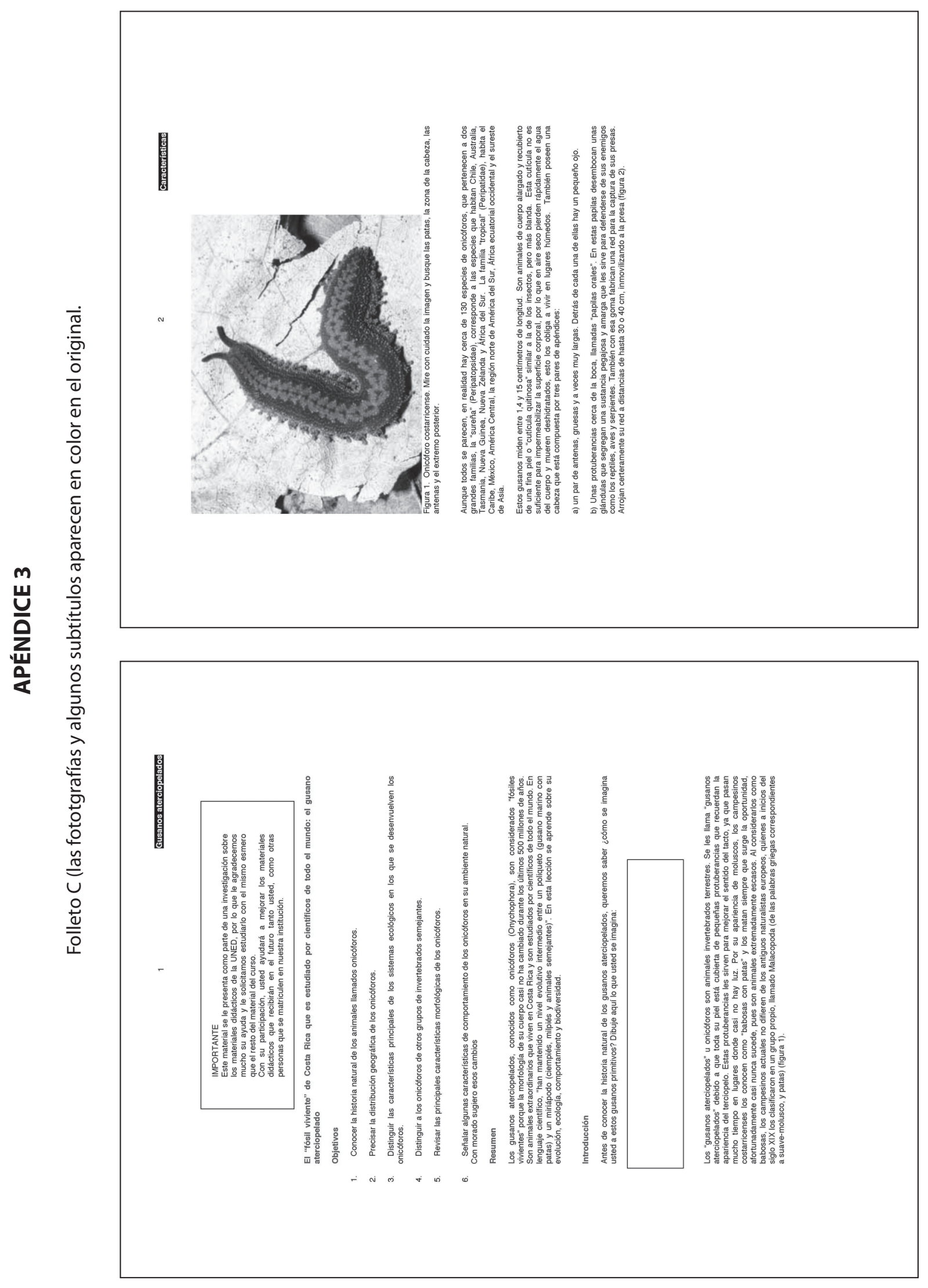



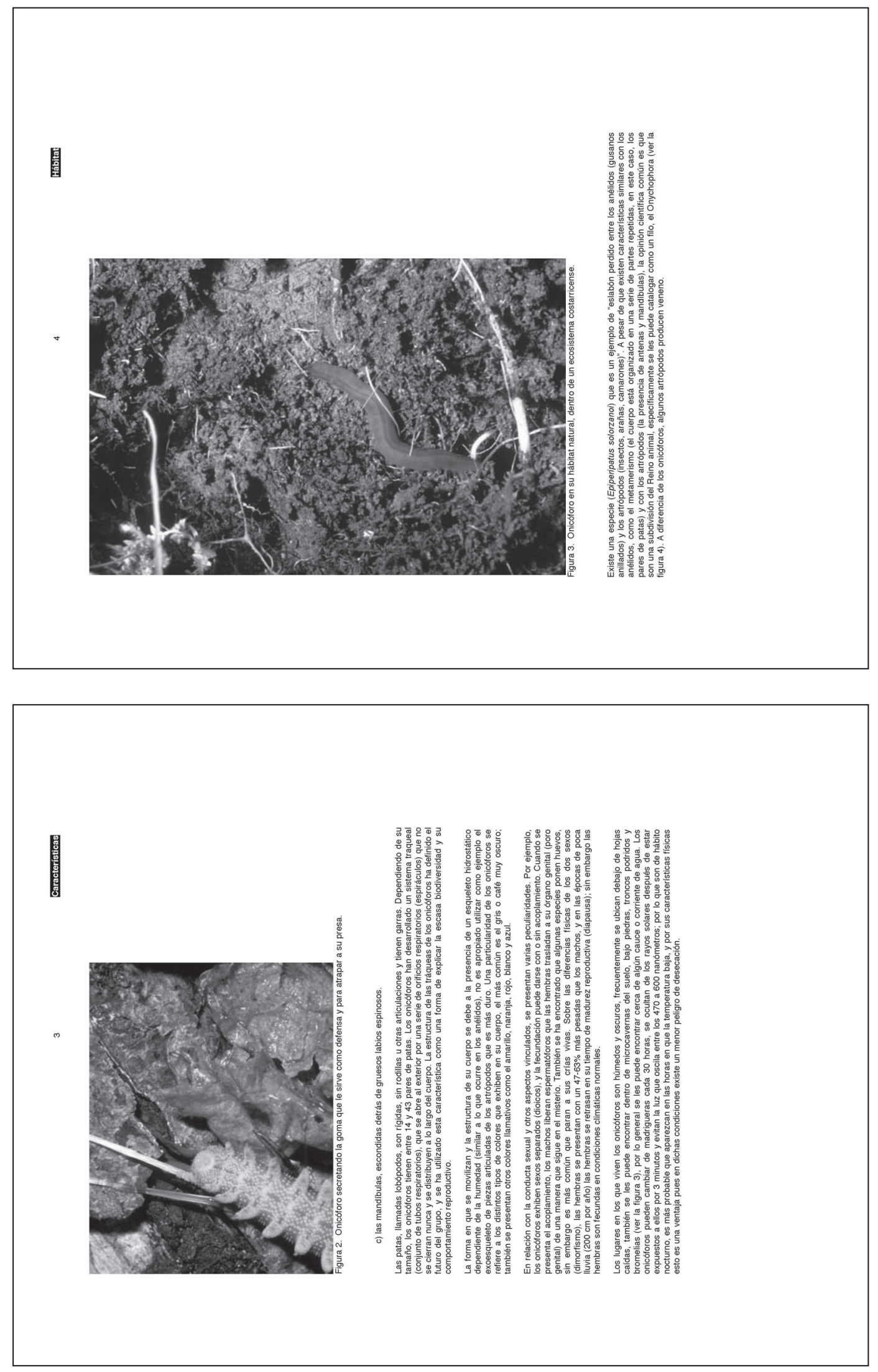

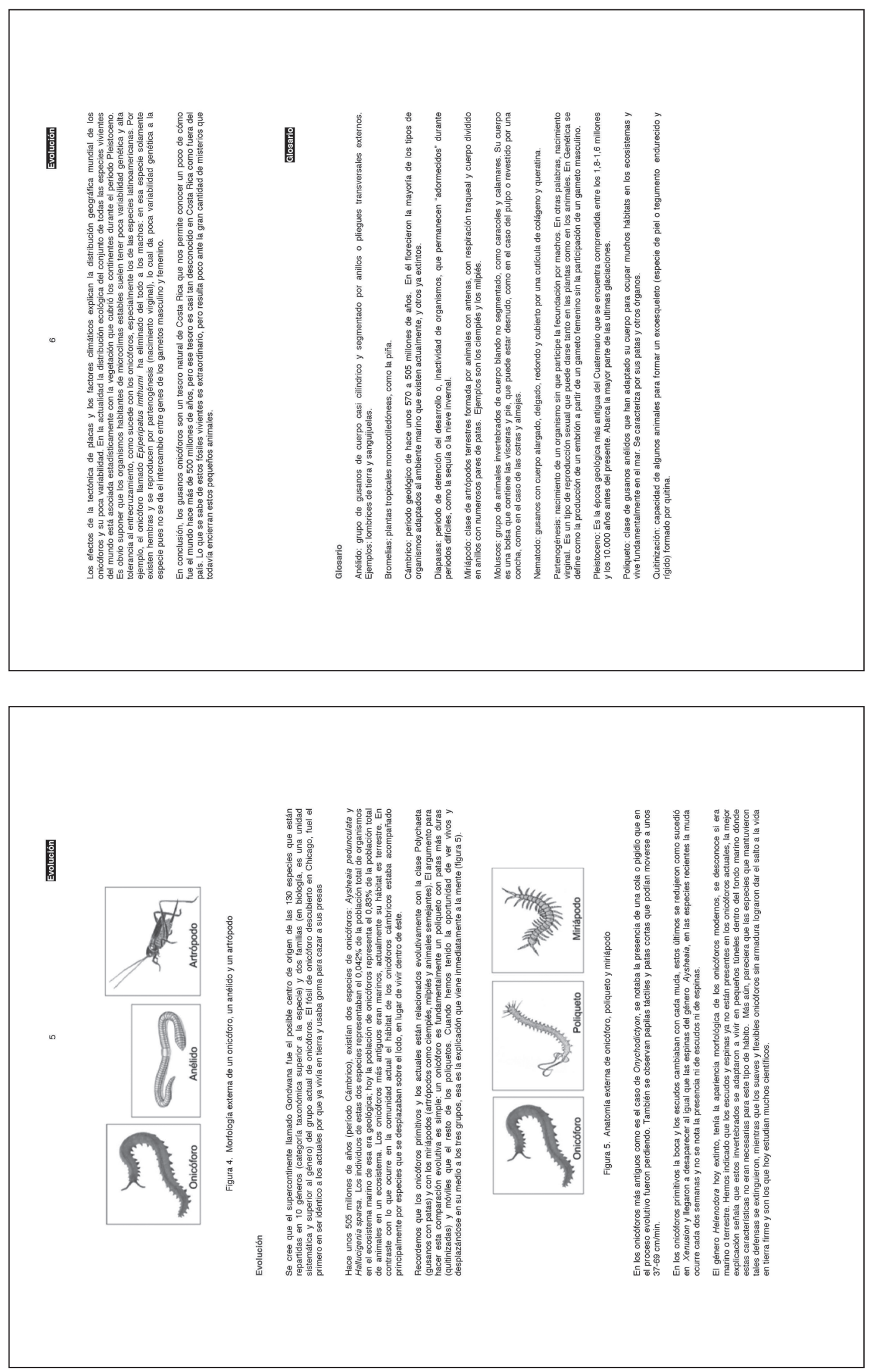

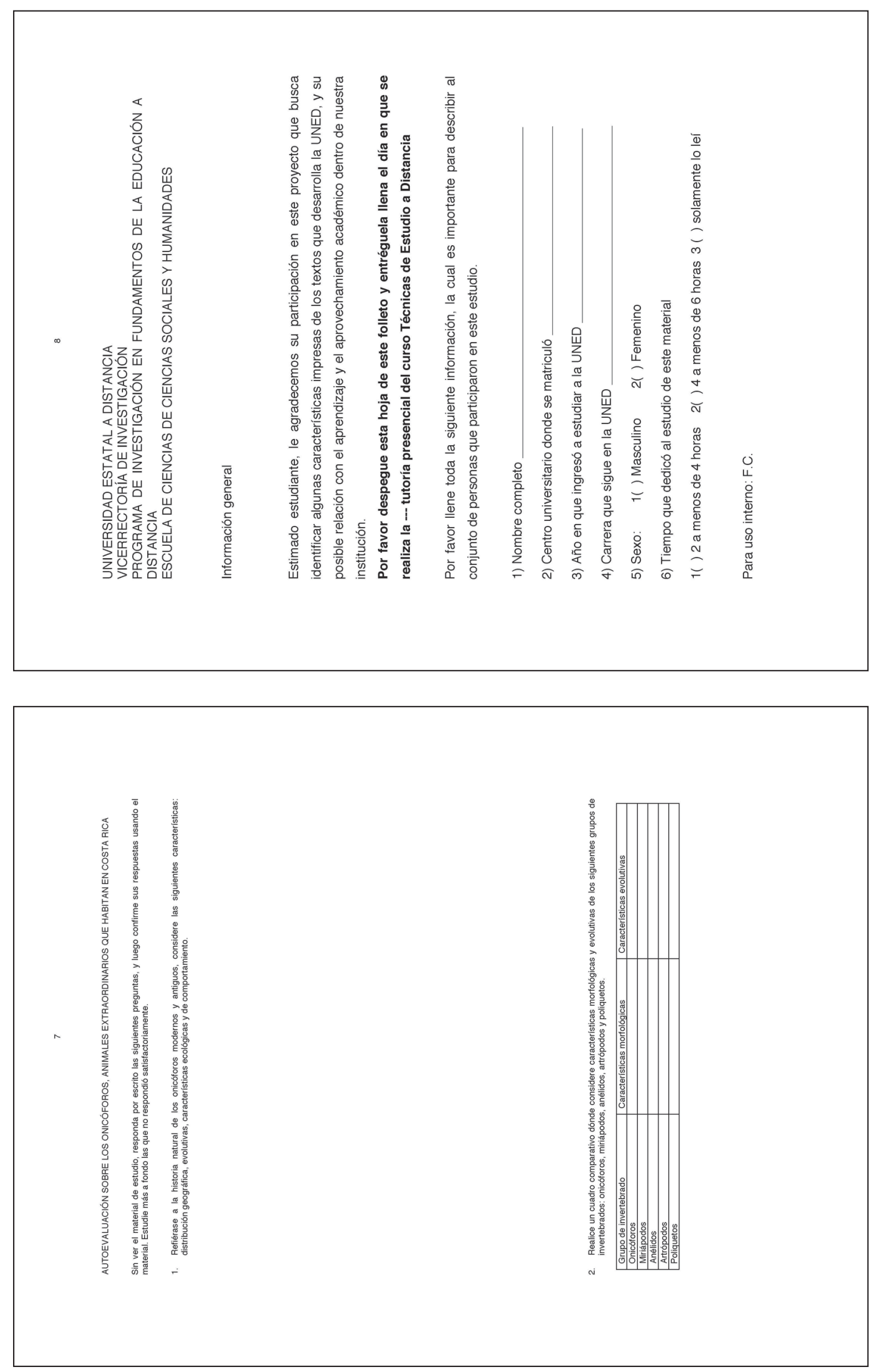

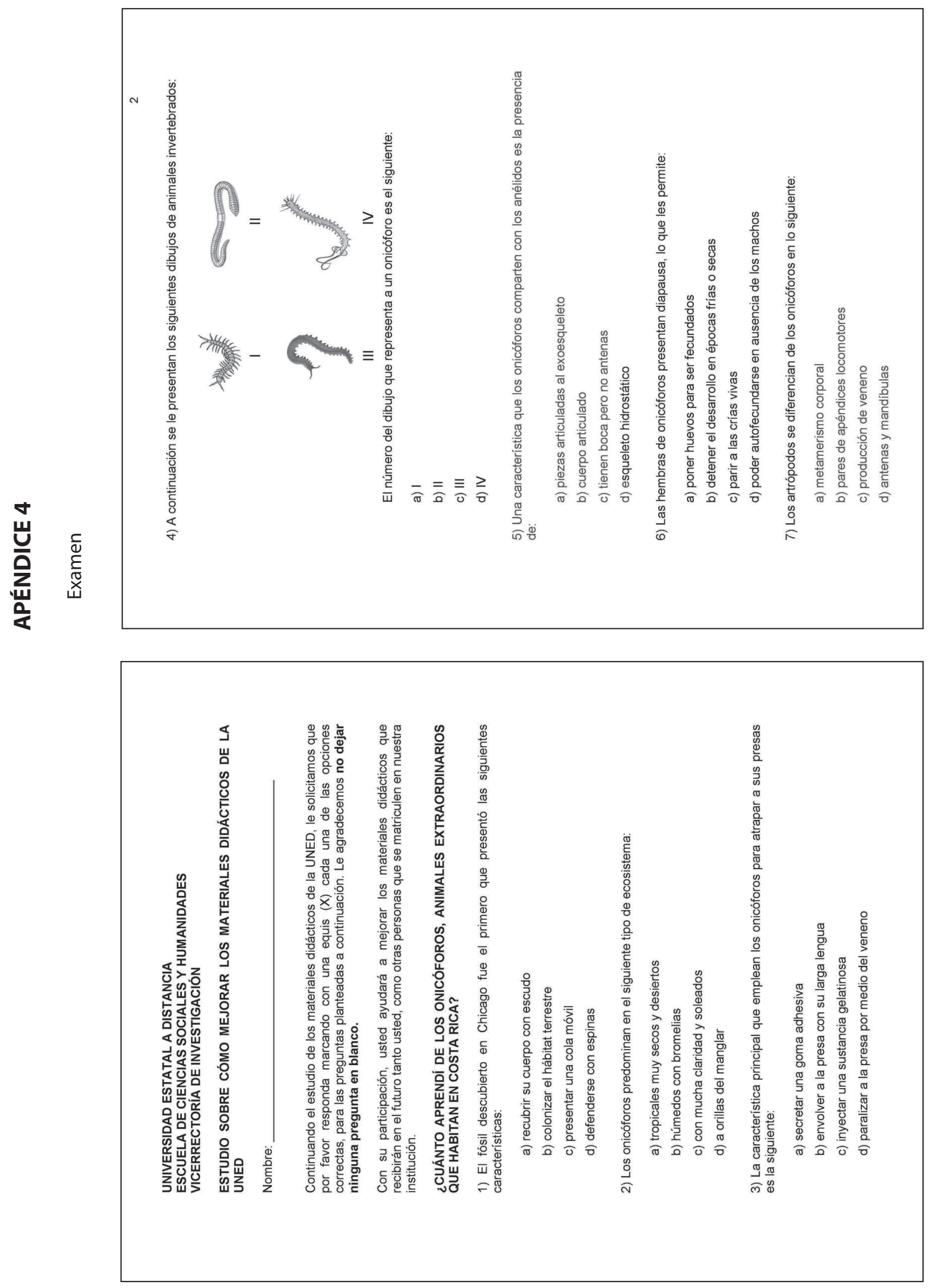

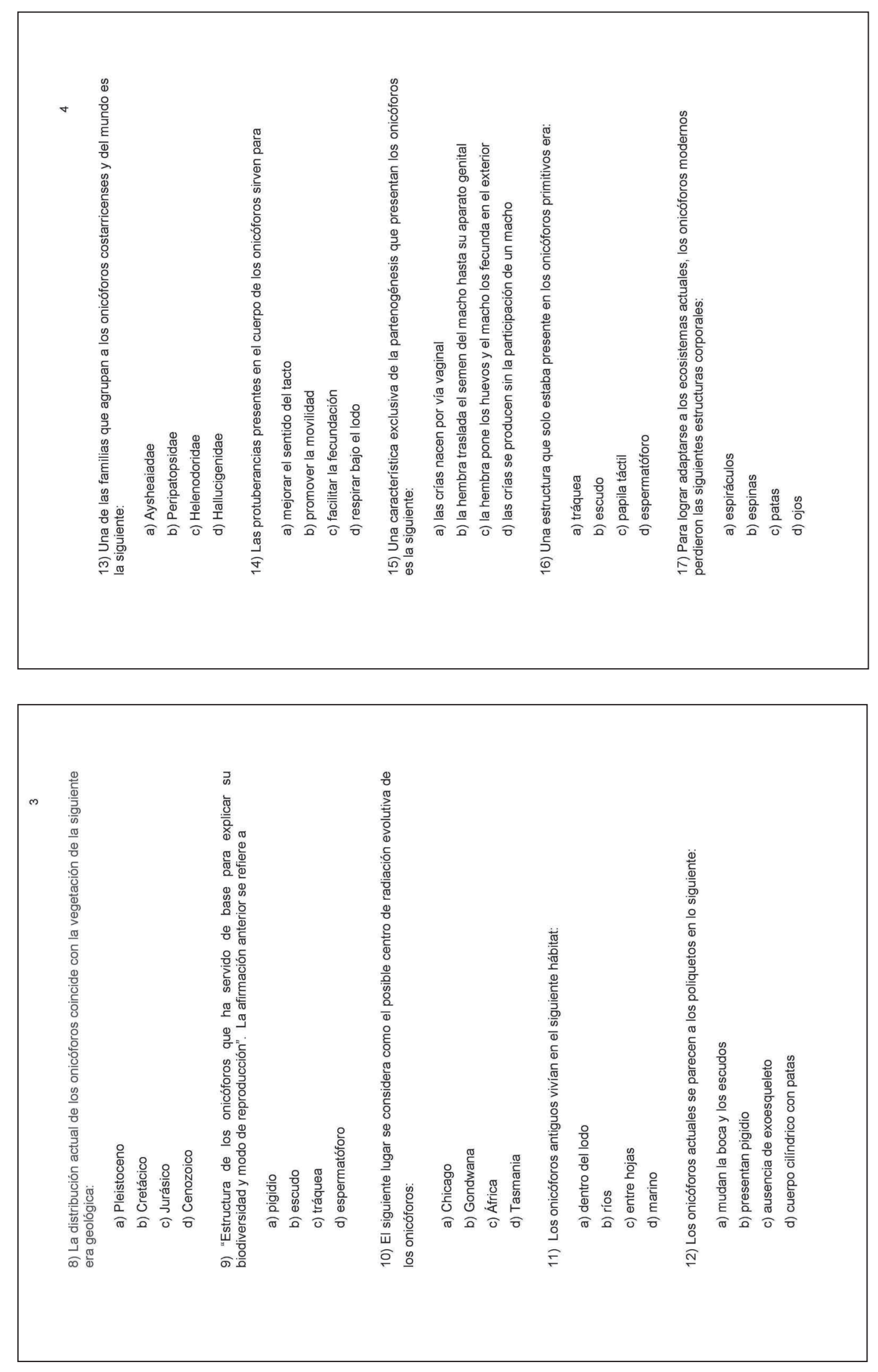


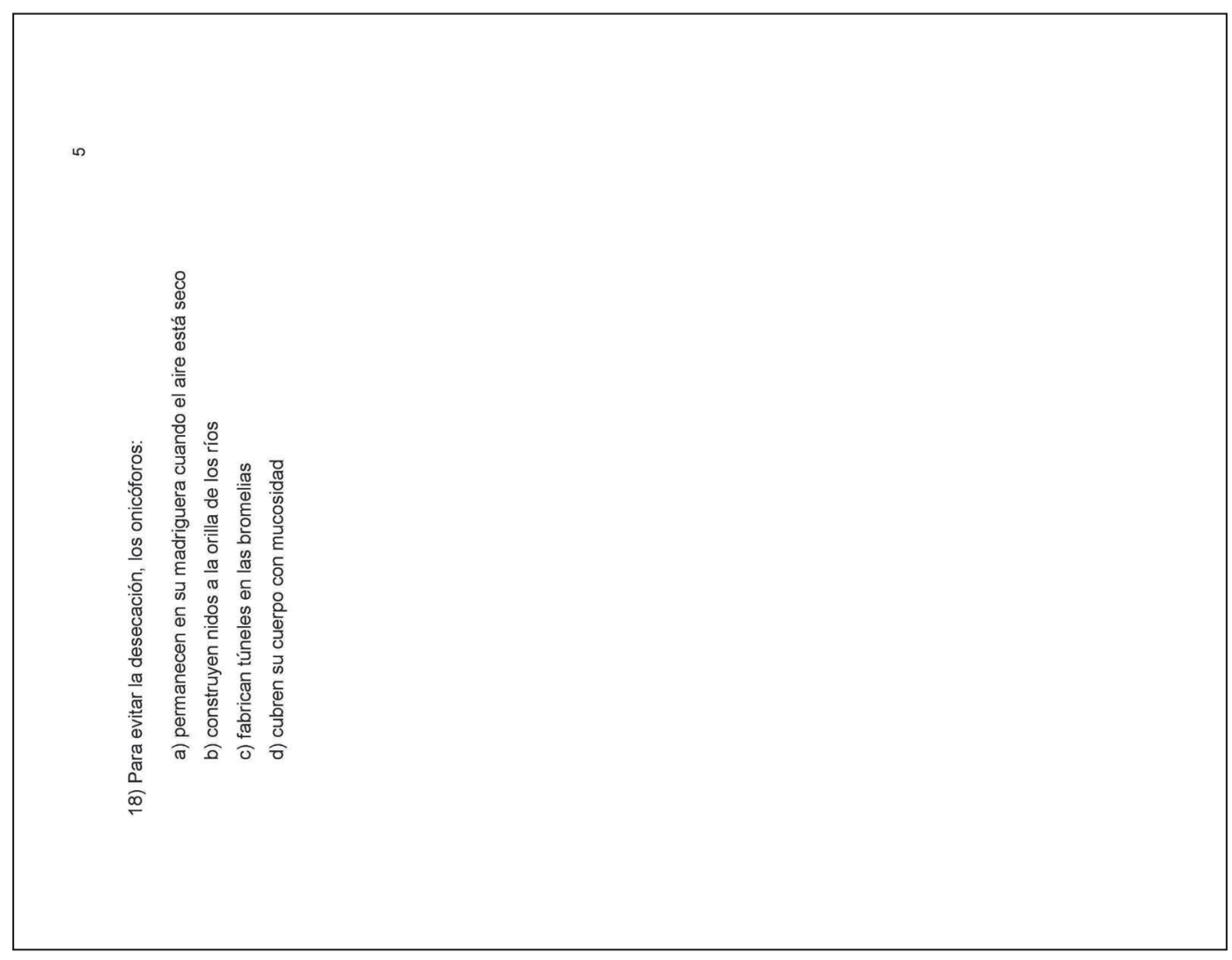




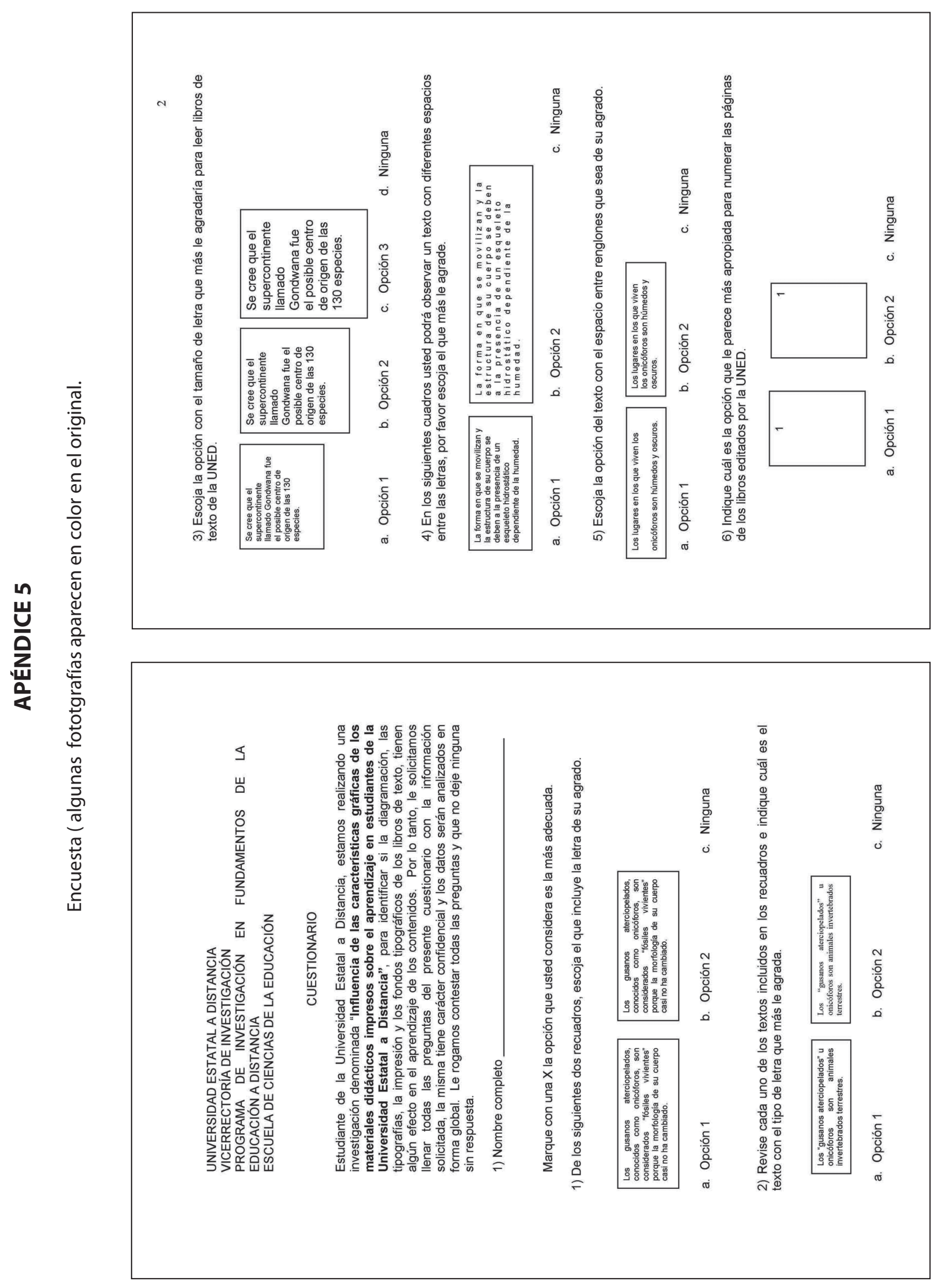



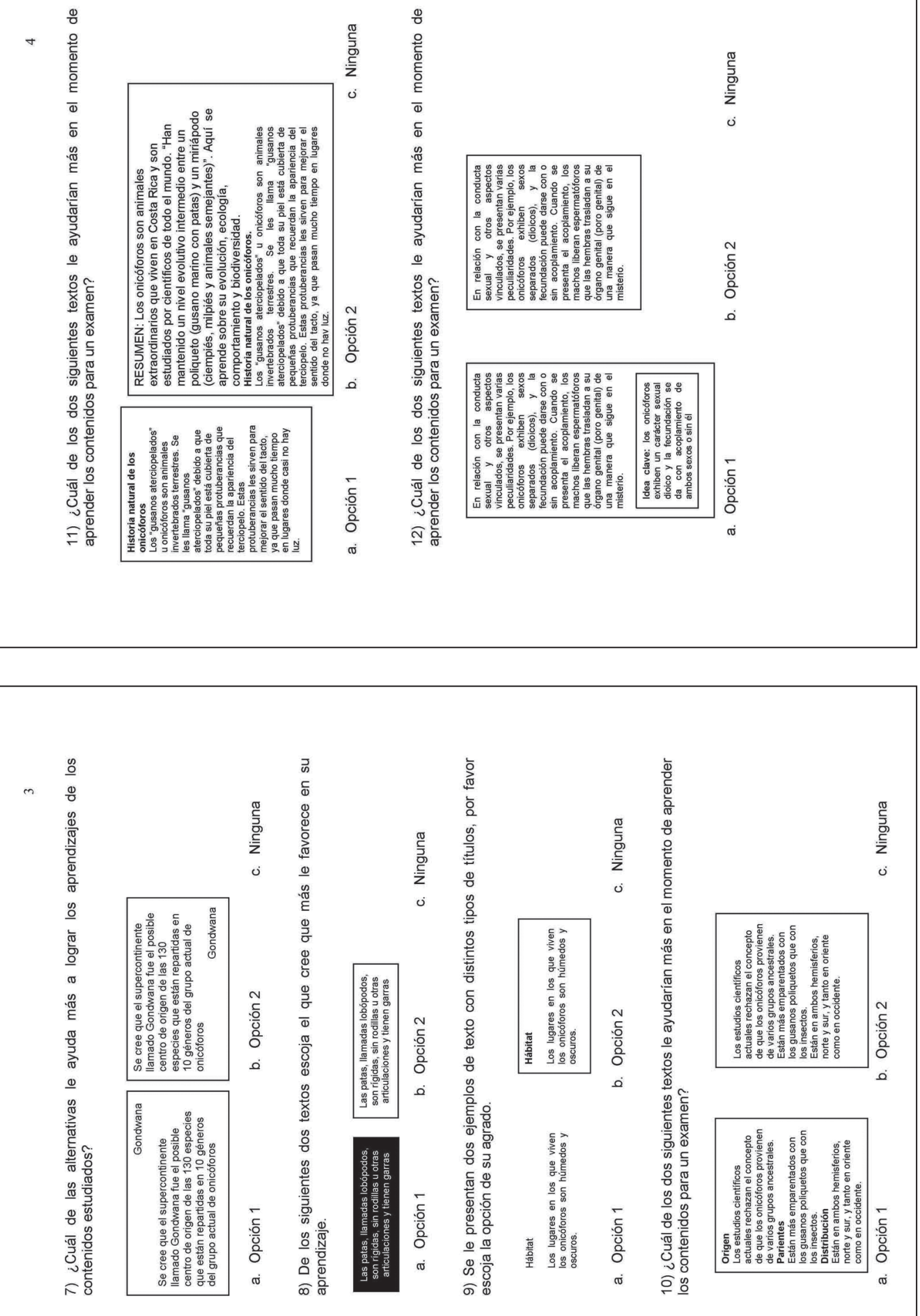


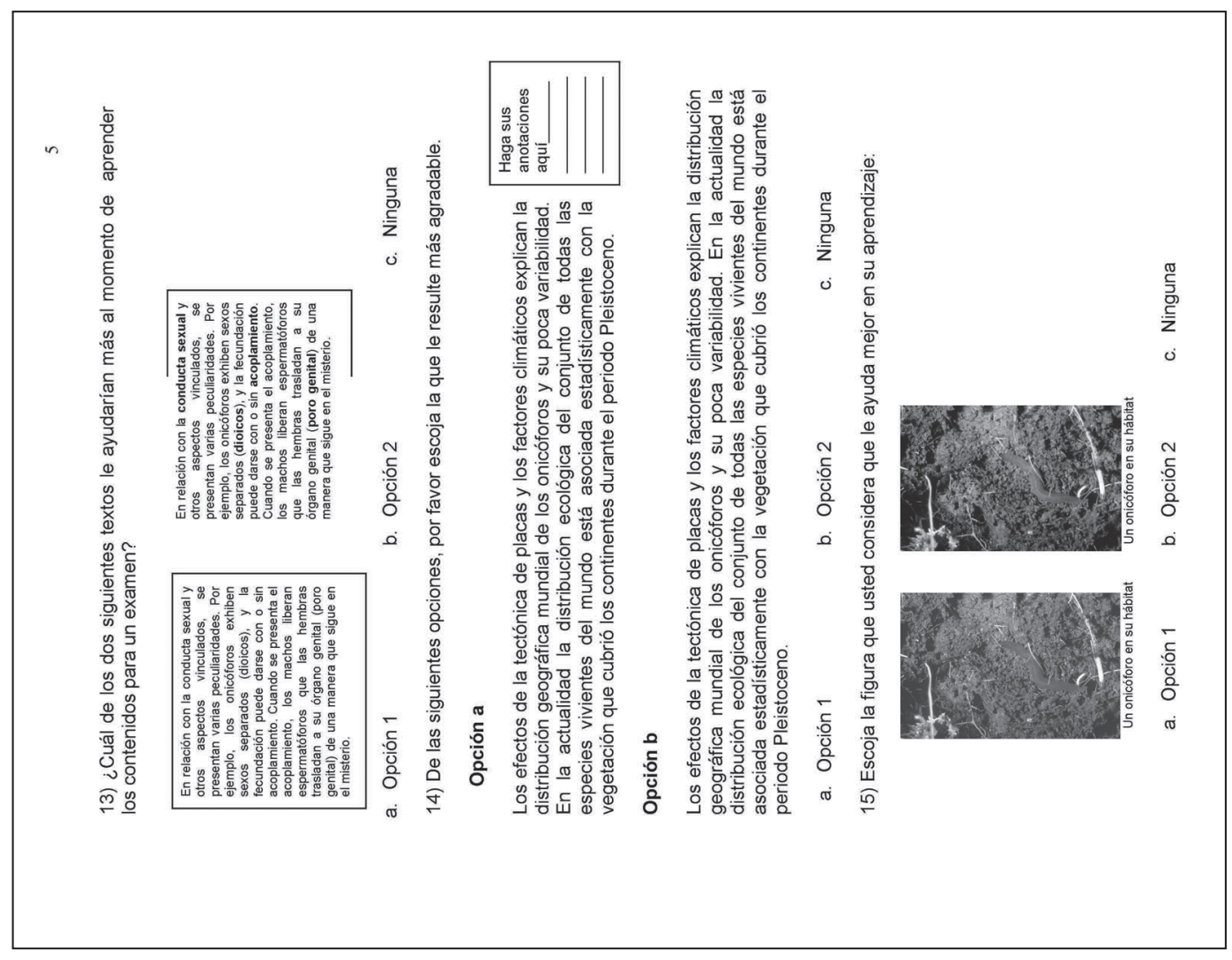

